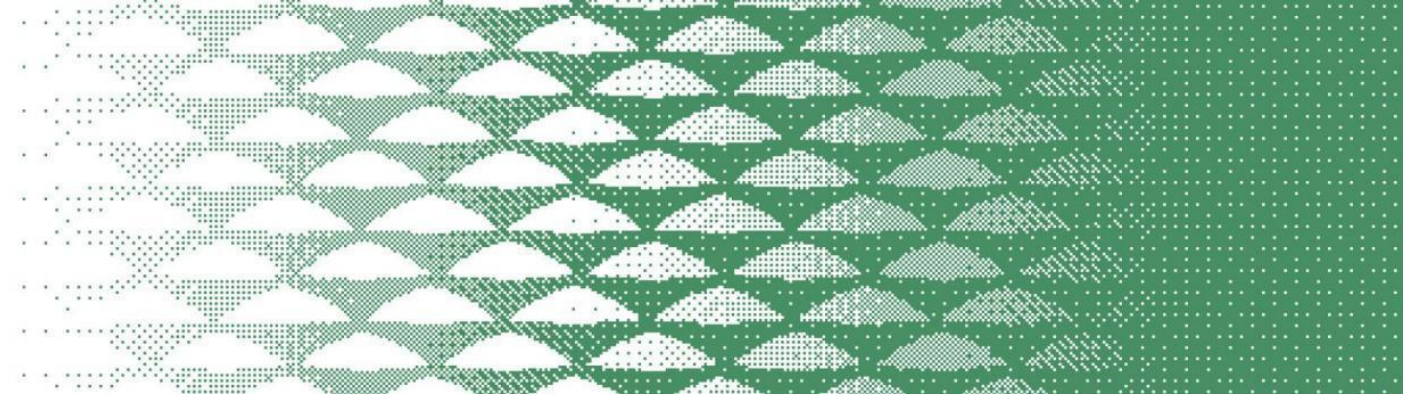

\title{
A intervenção do Design na educação inclusiva: livros digitais como proposta à redução das desigualdades no âmbito educacional da psicose infantil
}

\author{
Anne Ramayhara Mendes Gomes ${ }^{1}$; \\ Cássia Cordeiro Furtado²
}

resumo:

O fomento da pesquisa surgiu a partir da elaboração da questão que envolve em averiguar se os elementos da interface gráfica dos livros digitais auxiliam na inclusão do usuário infantil acometido pela estrutura psicótica. E o objetivo deste estudo é apresentar uma revisão sistemática de literatura, ao buscar por artigos, teses e dissertações nacionais e internacionais que abordem o tema do design de interação com os artefatos dos livros digitais. As bases de dados utilizadas para o levantamento das fontes bibliográficas foram a Scielo, Portal capes, Biblioteca de teses e disertassões e o Google school. Utilizou-se uma busca avançada, adotando os seguintes descritores em português e seus correspondentes em inglês para a pesquisa: psicose (psychosis) e design de interação (Interection design). Como critérios de inclusão foram considerados os artigos completos em inglês e português publicados nos últimos 5 anos, observados a partir da leitura do título e resumo/abstract. Foram excluídos desta revisão os artigos repetidos nas bases de dados; estudos em que o objetivo era de caráter meramente informativo a respeito da psicose e design de interação e não foram selecionados artigos que tratem da infância fora do contexto dos livros digitais e da psicose infantil não estando dentro do contexto educacional.

palavras-chave:

Design de Interação; Educação; Inclusão; Psicose Infantil; Livros Digitais

Espaço reservado para organização do congresso.

1 Endereço para acessar este CV: http://lattes.cnpq.br/7498125512918107

${ }^{2}$ Endereço para acessar este CV: http://lattes.cnpq.br/0332630687796918 


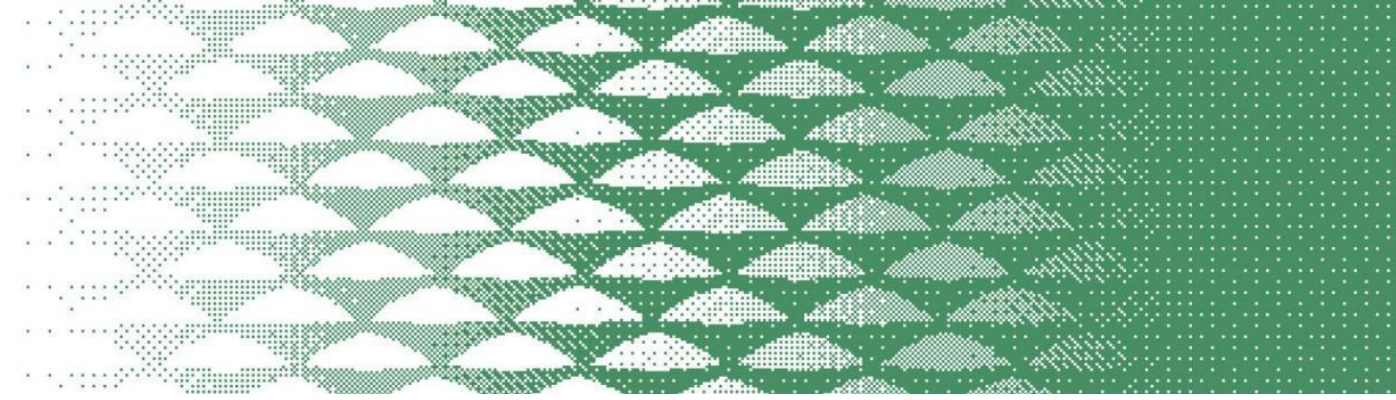

\section{Introdução}

O fomento da pesquisa surgiu a partir do questionamento que envolve em averiguar se os elementos da interface gráfica dos livros digitais auxiliam na inclusão do usuário infantil acometido pela estrutura psicótica.

O problema do trabalho consiste em desvelar, a partir da revisão sistemática de literatura realizada, de que forma o design de interação dos livros digitais podem contribuir para o processo de aprendizagem das crianças acometidas por psicose; logo, tem por objetivo compreender acerca dos contributos que o design de intreração do livro digital proporcionam à inclusão educacional de crianças diagnosticadas com psicose.

O presente trabalho é de grande relevância aos moldes educacionais inclusivos, haja vista que, há uma demanda quando se trata de crianças com desenvolvimento atípico, tanto por parte da estrutura educacional, quanto por parte da família que, por vezes, já se encontra fragilizada frente às dificuldades encontradas no âmbito biopsicossocial.

É comum crianças de desenvolvimento atípico apresentarem estereotipias, tiques ou comportamentos que na maioria das vezes não conseguem ser ministrados pela equipe escolar, são indivíduos que exibem atitudes desordenadas ou entram em profundo estado de catatonia.

Corrobora com a questão Moraes, Silva e Andrade (2007, p. 1) ao comentarem que "são indivíduos com taxas maiores de sintomas psicóticos, depressão, problemas escolares, hospitalização, ansiedade e comportamentos destrutivos.”, comenta sobre a questão Kupfer $(1996$, p. 1) ao atentar que são sujeitos que "fazem rápidas passagens pelas instituições escolares, "transferidas" - de fato, expulsas - de uma para outra, pois produzem um desassossego que não chega a ser nomeado pelos educadores. O que se diz sobre elas é que são "estranhas".

Segundo Moraes, S ilva e Andrade (2007, p. 20) na bipolaridade “(...) a criança é muito ativa, impulsiva, explosiva, fala em excesso e tem pouca necessidade de sono. Pode acreditar ter habilidades especiais ou poder fazer coisas impossíveis". Enquanto que na esquizofrenia apesar de se apresentar de diversas formas, existem sintomas que são peculiares a estrutura, sendo os principaís: delírios, alucinações; alterações do pensamento; alterações da afetividade; diminuição da motivação; dificuldade de concentração; alterações da motricidade; desconfiança excessiva e indiferença (CALABRI, 2010).

No ambiente escolar as dúvidas acerca do processo de educação destinadas à crianças com deficiência também perpassam pelo contexto destes educadores que na maioria das vezes não foram preparados para atender a demanda e isso deve-se a um currículo habilitado para trabalhar com a normalidade e quando a criança foge aos padrões acostumados, que não correspondem as exigências do êxito intelectual anunciados na contemporaneidade, acabam que deliberando certo sentimento de angústia e despreparo pelos atores envolvidos nesse enredo educacional (LEITE, 2006).

No entanto é diante desse cenário, de busca por alternativas no âmbito da educação de crianças psicóticas, que a proposta na experimentação dos livros digitais torna-se interessante, pois conforme Santos (2017) não é linear e nos traz a possibilidade de ter contato com várias mídias ao mesmo tempo (vídeo, áudio, imagem e texto). Corrobora Reis (2016) ao considerar que os livros digitais possibilitam ao usuário acessar blogs, videos, sites, jogos e redes sociais através dos links disponibilizados nos textos. Essa experiência do usuário com as interfaces do livro digital de acordo com Veras (2008) é determinante para desencadear as interpretações, cognitivas e significativas, sobre o artefato. Rogers, Sharp e Preece (2013) acentuam que "a experiência do usuário corresponde à preocupação central do Design de interação". Especificamente aos sentidos peculiares que os usuários expõem ao manuseá-los.

Para análise dos dados e discussão crítica foram utilizados quadro de amarração e protocolo para revisão sistemática de literatura, tendo como propósito levantar elaborações que contribuam para análise da pesquisa. 


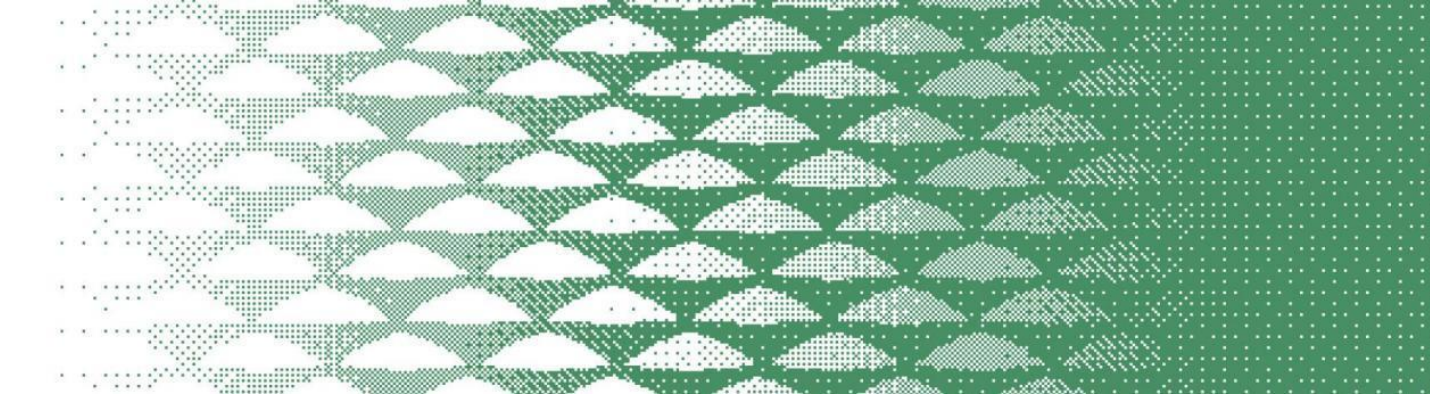

\section{0 Design de interação do livro digital como proposta à redução das desigualdades no âmbito educacional da psicose infantil}

No contexto escolar contemporâneo tem-se o recurso da leitura digital que torna-se interessante porque não é linear e nos traz a possibilidade de ter contato com vários elementos da interface gráfica do livro digital ao mesmo tempo (vídeo, áudio, imagem e texto), na qual compõe em seu aparato, movimento e interatividade entre o usuário (SANTOS, 2017).

Cauduru (2013, p. 9) aponta acerca da "importância de entender as mídias como fonte de conhecimento, objeto de estudo e forma de expressão para qualificar a educação, a partir de uma perspectiva crítica, criativa e responsável". Portanto esses dispositivos com seus hipertextos e suportes do registro do conhecimento apresentam novidades, pois mudam a forma de acesso, conteúdo, paginação, visualização, estímulo, interação e transmissão, mediação, pertinência, descobertas e concepção do ato de ler (CAUDURU, 2013).

Desse modo há uma interação entre o sujeito e o recurso, o que de acordo com Rogers, Sharp e Preece (2013) a interação compete em criar experiências de usuário que melhorem e ampliem a maneira como as pessoas trabalham, se comunicam e interagem. Então o foco do design de interação é pensar em como criar experiências de usuários.

Grilo (2015) aponta que tal aspecto possibilita que os produtos sejam pensados ou repensados levando em conta, sob a ótica do design centrado no usuário, os fatores humanos, como: habilidades, limitações, anseios, expectativas, frustrações, dentre outros.

Norman (2006) assinala que o "design é realmente um ato de comunicação, o que significa ter um profundo conhecimento da pessoa para quem o designer está se comunicando". Silva (2020) retrata que no design de interação dos objetos não existem fora do envolvimento humano; eles são construídos, compreendidos e reconhecidos na interação com as pessoas.

Veras (2008) corrobora ao apontar que essa busca pela interação faz com que o profissional do design tenha um pé no artefato e outro voltado para o Humano, aspecto observado nos livros digitais que trazem estímulos de acordo com a experiência de cada usuário. O estudo de Furtado (2017) relata que a introdução do artefato leitura digital possibilita criar laços sociais entre professor, aluno e familiares, assim como considera Martins (1994, p.31) quando retratam que a leitura "[...] é um espaço de interação consigo e com os outros cuja dinâmica envolve componentes sensoriais, emocionais, intelectuais, fisiológicos, neurológicos, bem como culturais, econômicos e políticos".

As famílias que possuem crianças dentro da estrutura psicótica se sentem na maioria das vezes sobrecarregadas e desorientadas quando o assunto corresponde à educação desses filhos que fogem aos padrões socialmente esperados; pontua Mannoni (1981, p. 175) em pesquisas realizadas com os pais a quem muitas vezes nos permite dizer: "não há nada a fazer". (...) Os pais não tem possibilidades de fazer viver o filho que, desde o inicio, está condenado a certo estado de desesperança. Então buscam por seguras alternativas no âmbito educacional, na espera que a sala de aula ofereça recursos estimulantes aos filhos.

A Constituição Federal de 1988, Art. 227, pontua sobre as leis que amparam a criança na sociedade, colaborando sobre a importância da família e do contexto social na constituição de sua formação, ponderando que: "[...] é dever da família, da sociedade e do Estado assegurar à criança e ao adolescente, com absoluta prioridade, o direito à vida, à saúde, à alimentação, à educação, ao lazer, à profissionalização [...]." (BRASIL, 1988, p. 144).

Em conformidade, a Política de Educação Especial (2017) aponta sobre o decreto 6.571/2008 (BRASIL, 2008, p.1), acerca dos objetivos propostos para o atendimento educacional especializado, destacado no Art. $2^{\circ}$, inciso IV sobre "assegurar condições para a continuidade de estudos nos demais níveis de ensino", considerando que é de suma importância proporcionar recursos para que as crianças acometidas por psicose prossigam no ambiente escolar, o que em paralelo ao trabalho em questão é visto sobre a possibilidade de inclusão dos livros digitais no parâmetro educacional da psicose infantil, levando em consideração a proposta de inclusão social. 


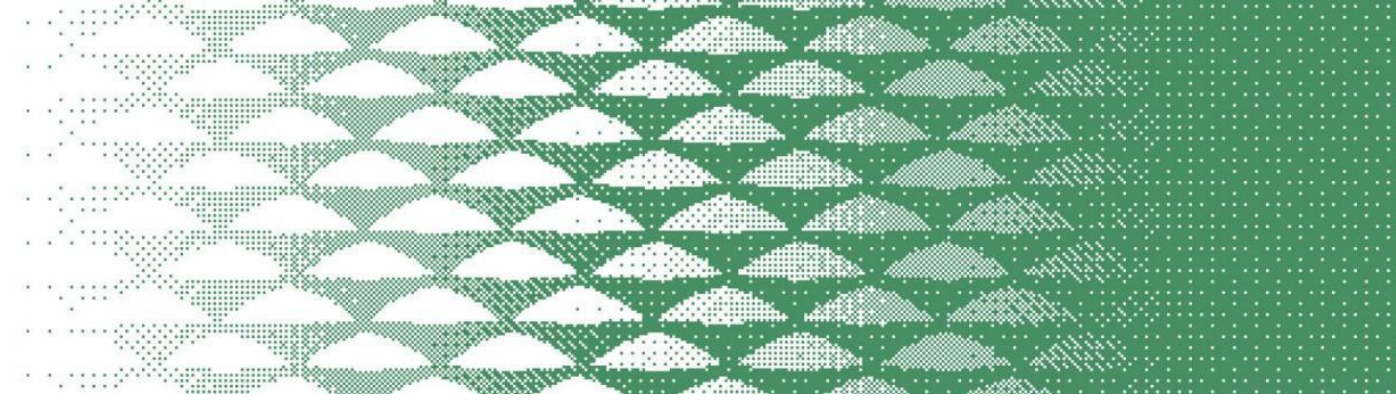

\section{Metodologia}

$\mathrm{O}$ artigo trata de uma revisão sistemática de literatura na qual segue os devidos critérios prescritos pelas etapas do processo: coleta de dados, análise de dados e síntese. Utilizou-se o protocolo de revisão sistemática e o quadro de amarração teórica que no primeiro momento possibilitou selecionar as palavras-chave, os critérios de inclusão e exclusão, selecionar o material para discursão, apontar as bases de dados e elaborar o problema da pesquisa.

As bases de dados utilizadas na pesquisa correspondem a Biblioteca de teses e dissertações, Scielo e o Portal Caps e o período de publicação das obras utilizadas datam de 5 anos, estando elas entre 2017 a 2021, pontuando que foram encontrado artigos anteriores que estavam dentro do critério de inclusão previsto, então foram selecionados.

Para a categoria de busca em língua portuguesa usou-se as palavras-chave e descritores como "livro digital AND psicose", "design de interação AND livro digital", "experiência do usuário AND livro digital", "design de informação AND livro digital" e "tecnologia assistiva AND desficiência mental" e para busca em língua inglesa foram usados os termos "digital book AND psychosis", "interaction design AND digital book", "user experience AND digital book" e "Assistive technology AND mental deficiency".

O contexto bibliográfico perpassou pelo levantamento de artigos, teses, e dissertações, que teve como propósito trabalhar na questão da pesquisa que consiste em desvelar como os elementos da interface gráfica dos livros digitais auxiliam na inclusão do usuário infantil acometido pela estrutura psicótica?

Em complemento às considerações teóricas pontua (AMARAL, 2007, p. 1) ao considerar que "a pesquisa bibliográfica é uma etapa fundamental em todo trabalho científico que influenciará todas as etapas de uma pesquisa, na medida em que der o embasamento teórico em que se baseará o trabalho" e contribuindo para a questão (LAKATOS E MARCONI, 2010) apontam que "[...] a pesquisa bibliográfica, já publicada sobre o assunto, tem o objetivo de colocar o pesquisador em contato direto com todo material escrito sobre o mesmo."

\subsection{Critérios de seleção: palavras-chaves e termos de pesquisa}

Quadro 1 - Critérios de seleção

\begin{tabular}{|l|l|l|l|}
\hline Base de Dados: & \multicolumn{1}{|c|}{ Tipo de documento: } & $\begin{array}{l}\text { Área de assunto: } \\
\text { BDTD }\end{array}$ & $\begin{array}{l}\text { Período: } \\
\text { ALL - }\end{array}$ \\
$\begin{array}{l}\text { SCIELO } \\
\text { PORTAL }\end{array}$ & $\begin{array}{l}\text { An "article title, } \\
\text { abstract, } \\
\text { CAPS }\end{array}$ & $\begin{array}{l}\text { Sciences \& } \\
\text { Humanites }\end{array}$ \\
$\begin{array}{l}\text { GOOGLE } \\
\text { SCHOOL }\end{array}$ & keywords" & $\begin{array}{l}\text { present (03 Ago } \\
\text { 2020) }\end{array}$ \\
\hline PESQUISA 1 & \multicolumn{1}{|c|}{ PESQUISA 2 } & PESQUISA 3 & PESQUISA 4 \\
\hline $\begin{array}{l}\text { "digital book } \\
\text { AND psychosis" }\end{array}$ & "interaction design AND digital \\
book" & $\begin{array}{l}\text { "user experience AND } \\
\text { digital book" }\end{array}$ & $\begin{array}{l}\text { "Assistive } \\
\text { technology AND } \\
\text { mental } \\
\text { deficiency" }\end{array}$ \\
\hline
\end{tabular}

Fonte: Gomes (2021) 


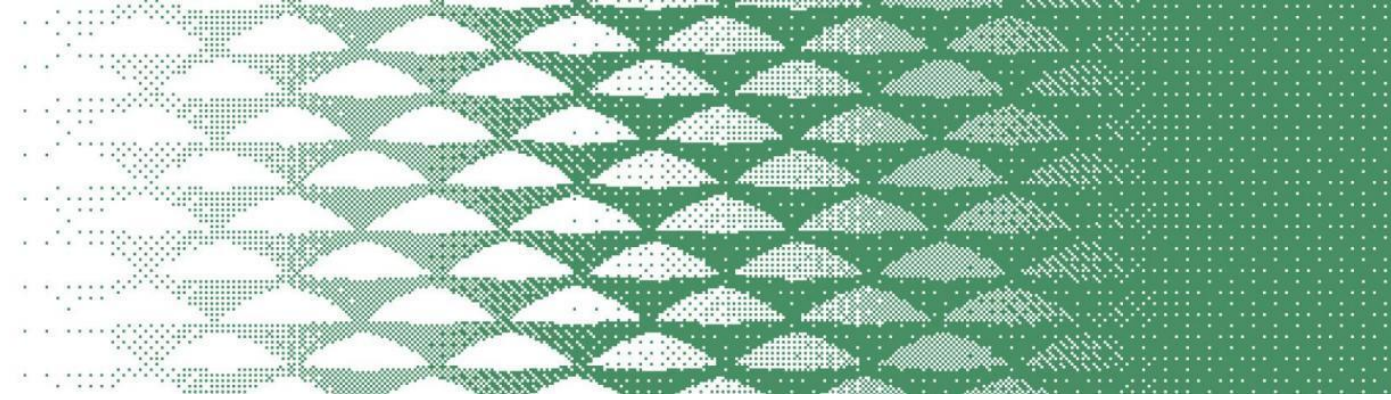

The intervention of Design in inclusive education: digital books as a proposal to reduce inequalities in the educational sphere of child psychosis

\begin{abstract}
The promotion of the research came from the elaboration of the question that involves in verifying if the elements of the graphic interface of the digital books help in the inclusion of the child user affected by the psychotic structure. And the aim of this study is to present a systematic literature review, searching for articles, theses and national and international dissertations that address the theme of interaction design with the artifacts of digital books. The databases used for the survey of bibliographic sources were Scielo, Portal Capes, Thesis and Dissertation Library and Google School. An advanced search was used, adopting the following descriptors in Portuguese and their English counterparts for the research: psychosis (psychosis) and interaction design (Interection design). As inclusion criteria, the complete articles in English and Portuguese published in the last 5 years were considered, observed from the reading of the title and abstract/abstract. Articles repeated in the databases were excluded from this review; studies in which the objective was merely informative about psychosis and interaction design, and articles dealing with childhood outside the context of digital books and child psychosis not being within the educational context were not selected.
\end{abstract}

Keywords: Interaction Design; Education; Inclusion; Child Psychosis; Digital Books

\title{
Referências bibliográficas
}

- Ministério da Saúde. Saúde mental no SUS: os centros de atenção psicossocial. Disponível em:<http://www.ccs.saude.gov.br/saude_mental/pdf/sm_sus.pdf>. Brasília: 2004. Acesso em: 5 de jul. de 2019.

. RESOLUÇÃO CFP No 018/2000 DE 20 DE DEZEMBRO DE 2000.Disponível em:

<http://www.crprs.org.br/upload/legislacao/legislacao15.pdf>. Acesso em: 15 de jul. de 2019.

\section{CONSELHO ESTADUAL DOS DIREITOS DA CRIANÇA E DO}

ADOLESCENTE. Disponível em:<estatuto-da-crianca-e-do-adolescente-versao-2019.pdf (www.gov.br).>. Acesso em: 18 de jul. de 2019.

CAUDURU, Lenice. Mídia e Educação: novos olhares para a aprendizagem sem fronteiras. Pesquisa em mídia-educação no contexto escolar: do cruzamento de olhares o encontro de pistas. Raul Inácio Busarello, Patricia Bieging e Vania Ribas Ulbricht, organizadores. - São Paulo: Pimenta Cultural, 2013.

CALABRI, Suely. Esquizofrenia: doença mental e seu processo no ensino e aprendizagem. Publicado em 11 de September de 2010. Disponível em:

<https://www.webartigos.com/artigos/esquizofrenia-doenca-mental-e-seu-processono- ensino-aprendizagem/46945>. Acesso em: 02 de ago. de 2019.

MORAES, Cesar de; SILVA, Fábio Mello e ANDRADE, Énio de Rocha. Diagnóstico e tratamento de transtorno bipolar e TDAH na infância: desafios na prática clínica. Disponível em <http://www.scielo.br/scielo.php?script=sci_arttext\&pid=S0047- 20852007000500005 >. Acesso em: 10 de nov de 2019. 
MANTOAN, M.T.E. (org). Caminhos pedagógicos da inclusão: como estamos implementando a educação (de qualidade) para todos nas escolas brasileira. São Paulo: Memmon, 2011. Disponível em:

<http://www.lite.fe.unicamp.br/papet/2003/ep403/caminhos_pedagogicos_da_inclusa o. htm>. Acesso em: 10 de out. de 2019

NORMAN, Donald A. O Design do dia-a-dia. Tradução: Ana Deiró. - Rio de Janeiro: Rocco, 2006.

FILENO, Erico. Design de Interação e inovação: palestra realizada na Campus Party Brasil 2013. Disponível em: <https://pt.slideshare.net/efileno/design-de-interao-e-inovao>. Acesso em: 01. Fev. 2021.

OLIVEIRA, Ildeu Baptista. Ensaio sobre o Real, o Simbólico e o Imaginário. Dezembro, 2010. Disponível em: <http://sobramesmg.org.br/novo/ensaio>. Acesso em 7 de ago. de 2019

FURTADO, Cassia Cordeiro. 0 uso das tecnologias digitais de informação e comunicação para o desenvolvimento das competências de leitura, comunicação e produção da comunidade escolar da rede pública da educação básica do Maranhão. Edital Fapema no 031/2016 Universal: 2017.

FREUD, Anna. Infância normal e patológica. Editora: Zahar, 1965.

GRILO, André. Psicologia Comportamental e Design de Interação. Disponível em: $<$ https://brasil.uxdesign.cc/psicologia-comportamental-e-design-de-intera\%C3\%A7\%C3\%A3o1de3f46b25e8>. Acessado em: 29. Jan. 2021.

GOMES, Anne Ramayhara Mendes, FURTADO, Cassia Cordeiro e CARVALHO, Silvestre Matos de. $\mathbf{0}$ uso dos Smartphones por Alunos do Ensino Fundamental: resultado de pesquisa em escola pública de São Luís- MA. Disponível em: <http://tecedu.pro.br/wp-content/uploads/2017/10/Art26vol.22-Edi\%C3\%A7\%C3\%A30-Tem\%C3\%A1tica-VI-Outubro-2017.pdf> . Acesso em: 10 de Jun. de 2018.

CARVALHO, Daniella. Mídias Dinâmicas em Book Apps Infantis: a experiência do usuário infantil enquanto a prática da leitura. 2017. 174 f. Dissertação (Mestrado em Design) - Universidade Federal do Maranhão, São Luís, 2017. Disponível

em:<https://webcache.googleusercontent.com/search?q=cache:xIFIdiC7g3UJ:https://tedebc.ufma.br/ jspui/handle/tede/1665+\&cd=1\&hl=pt-BR\&ct=clnk\&gl=br>. Acesso em: 7. Jan. de 2021.

SAFFER, Dan. Designing for interaction. Second Edition. Disponível em: < https://brasil.uxdesign.cc/tagged/dan-saffer>. Acesso em: 01. Fev. 2021.

SILVA, Malileze Geralda. Crianças diagnósticadas com TDAH: expectativas e acompanhamento dos pais. São Luis: EDUFMA, 2009. Disponível em $<$ http://www.edufma.ufma.br/index.php/produto/criancas-diagnosticadas-com-tdah- expectativas-eacompanhamento-dos-pais/>. Acessado em 6 de out. de 2019.

SOUSA, Maria Eliziana Pereira de; TARGINO, Maria das Graças. Cinco leis da biblioteconomia / cinco leis de Ranganathan: resistindo bravamente ao tempo. Ci. Inf. Rev., Maceió, v. 3, n. 1, p. 11-29, jan./abr. 2016. Disponível em: <http://www.seer.ufal.br/index.php/cir/article/view/2334/1840>. Acesso em: 10 de fevereiro de 2018.

KUPFER, M. Cristina. A presença da psicanálise nos dispositivos institucionais de tratamento da psicose. Estilos clin. vol.1 no.1 São Paulo 1996. Disponível em: 
<http://pepsic.bvsalud.org/scielo.php?script=sci_arttext\&pid=S1415-71281996000100003>. Acesso em 8 de Nov. de 2019.

KROEFF, Paulo. A pessoa com deficiência e o sistema familiar. $\mathbf{X}$ congresso Brasileiro de terapia familiar, da ABRATEF. Curitiba - PR, Julho de 2012. Disponível em <http://www.abratef.org.br/backup-2012/anaiscongresso2012/>. Acesso em: 2 de out. de 2019.

GODOY, Arllda Schmidt. Introdução à pesquisa qualitativa e suas possibilidades. Revista de Administração de Empresas. Disponível em:< http://www.wejconsultoria.com.br/site/wpcontent/uploads/2015/04/Introdu\%C3\%A7\%C3\%A3o-\%C3\%A0-Pesquisa-qualitativa-e-suaspossibilidades.pdf

LEITE, Zinole Helena. Inclusão escolar de alunos com deficiência mental no ensino fundamental: entre o possível e o desejável. UFMA: 2006, Mestrado em Educação. Disponível em:

<http://tedebc.ufma.br:8080/jspui/bitstream/tede/122/1/Zinole\%20Leite.pdf>. Acesso em: 5 de nov. de 2019.

MARCONI, M. de A.; LAKATOS, E. M. Metodologia científica. São Paulo, SP: Atlas, 2010

MANNONI, Maud. A criança atrasada e a mãe. Editora: Moraes, 1981.

MARTINS, Maria Helena. O que é leitura. 19. ed. São Paulo: Brasiliense, 1994.

MINETTO, Maria de Fátima. et al. Práticas educativas e estresse parental de pais de crianças pequenas com desenvolvimento típico e atípico. Educ. rev. [online]. 2012, n.43, pp.117-132. ISSN 0104-4060.

NEVES, Pablo Diego de Araújo. Implicações do uso de smartphones como ferramentas de interatividade para participação no contexto da celebração da santa missa. Disponível em: < https://tedebc.ufma.br/jspui/handle/tede/638>. Acessado em 10. Jan. 2021

PASSOS, Eduardo; KASTRUP, Virgínia; ESCÓSSIA, Liliana da. PISTAS DO MÉTODO DA REIS, Edilson Thialison da Silva. Usuário infantil e ebook: um olhar para o Portal Biblon. 2016. 123 f. Dissertação (Mestrado em Design) - Universidade Federal do Maranhão, São Luís, 2016. Disponível em: <https://tede2.ufma.br/jspui/handle/tede/644>. Acessado em 10. Jan. 2021.

ROGERS, Yvonne; SHARP, Helen; PREECE, Jennifer. Design de interação: além da interação humano-computador; Tradução: Isabela Gasparini; Revisão técnica: Marcelo Soares Pimenta. 3. ed. Dados eletrônicos. - Porto Alegre: Bookman, 2013.

VASQUES, Carla K. Um Coelho Branco Sobre a Neve Estudo sobre a Escolarização de Sujeitos com Psicose Infantil. Disponível em: https://lume.ufrgs.br/handle/10183/3811. Acesso em: 18. Jan. 2021.

VERAS, Ana Cristina de. Design e Psicologia: aplicando conceitos de Psicologia em Design. Dissertação (Mestrado) - Universidade Federal de Pernambuco. CAC. Design, 2008. Disponível em: <https://repositorio.ufpe.br/bitstream/123456789/3071/1/arquivo2177_1.pdf> . Acesso em: 08. Fev. 2021.

WINNICOTT, D.W. A criança e o seu mundo. 4 ed. Editora: Zahar, 1957. 